\title{
Vaginal foreign body in a 6 year old girl: a game for the child but a challenge for the gynaecologist
}

\author{
Amrita Chaurasia, Veena Gupta, Akanksha Mishra*
}

Department of Obstetrics \& Gynaecology, M.L.N Medical College, Allahabad, Uttar Pradesh, India

Received: 17 February 2015

Accepted: 01 March 2015

\section{*Correspondence:}

Dr. Akanksha Mishra,

E-mail: dr.akanksha.gsvm@gmail.com

Copyright: () the author(s), publisher and licensee Medip Academy. This is an open-access article distributed under the terms of the Creative Commons Attribution Non-Commercial License, which permits unrestricted non-commercial use, distribution, and reproduction in any medium, provided the original work is properly cited.

\begin{abstract}
A 6 year old girl visited our gynaecology out-patient department of S.R.N hospital, Allahabad, India with the complaint of relapsing blood stained vaginal discharge for 3 months. Different gynaecologists, including us, tried treating the condition with different courses of antibiotics. To each, the girl responded only for few days and relapsed again. We investigated completely into the background of the child's home and school environment, her playing habits and her behaviour with her kins. Then, we got her various investigations done but with no derangement. With the backup of her history, examination and investigations, we performed another detailed examination of her genitals. The findings were intriguing as to their cause, and it definitely was a lesson to all of us.
\end{abstract}

Keywords: Vaginal discharge, Relapsing, Vaginitis, Vaginal foreign body, Antibiotics

\section{INTRODUCTION}

Vaginal discharge in a prepubertal girl is usually not worrisome if it is treated once and for all as these girls are a little bit more predisposed to vaginitis due to lack of the estrogenic protective effect of vaginal acidity and multilayered vaginal epithelium. But once it becomes blood stained or relapsing and resistant kind of discharge, definitely it generates a major concern in the guardians as well as the treating clinician because it may represent some important underlying etiologies like sexual abuse, trauma, endocrinological abnormality or vaginal tumors.

A variety of foreign bodies in the vagina like safety pins, hair pins, buttons, grains or a piece of toilet paper has been described in the literatures. ${ }^{1,2}$ They usually present with recurrent, blood stained, foul smelling discharge that may be associated with vulval and vaginal inflammation. ${ }^{3}$ Diagnosis may require just a careful examination of the vagina or sometimes a plain radiograph, ultrasound or MRI scan done for some other reason may raise the suspicion of a foreign body. Once diagnosed, removal of that foreign body is the definitive treatment.

Here we present a case of 6 years old girl who had malodorous, blood stained discharge for 3 months and was treated with multiple courses of antibiotics but got relieved completely only when we diagnosed the presence of foreign body in the vagina and removed it.

\section{CASE REPORT}

A 6 years old girl came to the out-patient department of S.R.N hospital, Allahabad with her mother. She was very much worried as her 6 years old daughter was having off and on bloody spots and blood mixed discharge from vagina since 3 months. Before coming to us, she visited many gynaecologists and had taken many courses of various antibiotics. On further interrogation, we found that she was younger of the two daughters to a single mother. Her parents got divorced 3 years back and she was living with her mother and sister in her maternal 
grandparents' house. There was harmonious relationship in the family. She also had good school performance and no behavioral abnormalities. Her mother was, although, more worried with suspicion of any sexual abuse in the home or school and simultaneously with concerns of premature menarche.

On examination, her general and systemic examinations were normal with no evidence of thelarche or adrenarche. She was mentally sound.

On genital examination, her underpants were found to be stained with blood spots. No active bleeding was there but medial sides of the labia was reddened and inflamed near vaginal orifice. On separating her labia, foul smelling blood stained discharge was seen. The vulva and hymen were intact without any obvious sign of sexual abuse.

Discharge was sent for culture and sensitivity test. Her bleeding and coagulation profile along with the complete blood count and hormonal assays were advised to rule out the possibility of any bleeding and coagulation disorder as well as precocious puberty. Urine analysis and culture was sent. She was also advised to get an abdominal ultrasonographic examination. Awaiting the reports, we gave her hemostastics and a course of antibiotic of cephalosporin group considering the foul smelling vaginal discharge. We also gave her lactobacilli containing perineal wash for good hygiene. All the investigations were normal with sterile culture, probably due to the antibiotics she had already taken. At the follow up visit after 7 days she was absolutely happy with no complaints. But it was only temporary, as her problems relapsed after a fortnight.

Taking her history, physical findings and normal investigations under consideration, we counseled her for more careful examination of her external genitals. On gently separating the labia we could visualize the lower vagina, that was inflamed and surprisingly we could see some dark suspicious object in her lower vagina. It was removed at the same time with a small artery forceps. To all our surprise it was found to be a small speck of discolored paper. Removal of a vaginal foreign body in outdoor is usually not possible and the procedure almost always requires anaesthesia. In this case, we could do it in the outdoor only because the girl was very cooperative as well as the foreign body was in the lower portion of vagina, after that vulva was washed with betadine solution.

I showed that piece of paper to the girl and her mother and inquired the little girl about the presence of that piece of paper in her vagina but she refused to tell anything. For more intimate and confidential talk I asked her mother and everybody else to go out of the room, and this time confiding in me, she told that while playing the game of 'Doctor and patient' with her sister that piece of paper was put in her vagina by her sister. I felt like I just had won something. Later on, she did well. Her vaginal discharge and spotting stopped completely and the patient improved remarkably.

Consent was given by the caregiver for this report.

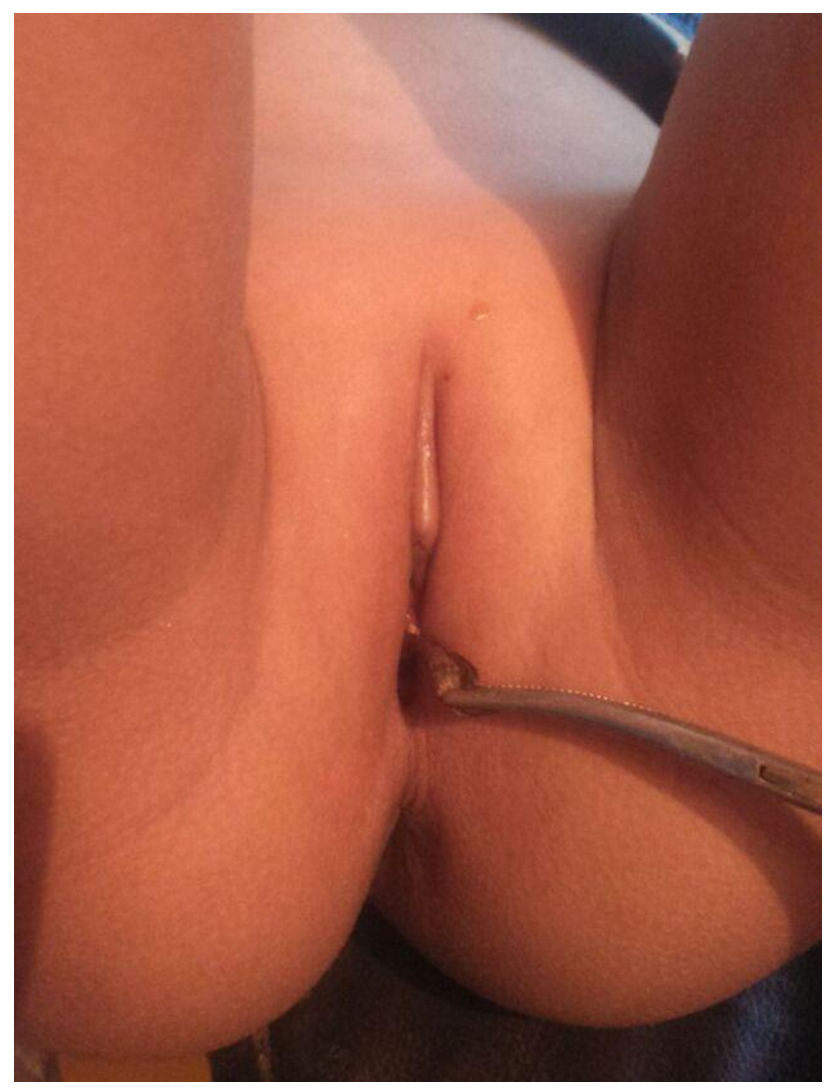

Figure 1: Showing foreign body.

\section{DISCUSSION}

Although foreign body in the vagina has been described both in adults and children, it's possibility is observed more in children. According to the studies by Di Miliago et al., ${ }^{4}$ Paradise et al., ${ }^{1}$ Deligeoroglou et al., ${ }^{5} 4 \%-5 \%$ of all prepubertal girls who visit gynecological outdoor for some problem had complains related to foreign body in the vagina. In another study by Capraro VJ et al., the incidence of foreign body in the vagina was found to be $10 \%$ in the prepubertal girls presenting with bloody discharge. ${ }^{6}$

Foreign bodies reach vagina either accidently or are deliberately put by the child herself or her sibling while playing. Their innocence and a curiosity to explore the natural orifices may force them to do so. Sometimes it may even be the manifestation of sexual abuse or psychogenic problem. The symptommatology usually include relapsing, foul smelling, blood stained vaginal discharge. Striker et al. ${ }^{2}$ reported that $50 \%$ of the girls with foreign body either presented with vaginal bleeding or blood stained discharge whereas Di Miliago et al. ${ }^{4}$ found that spotting, bleeding or bloody discharge as the most conspicuous symptom with $93 \%$ prevalence. Long 
standing effect of a foreign body varies with the nature and shape of the object. It may lead to perforation, abrasion, traumatic ulceration, pressure necrosis, fistula formation, vaginal stenosis or fibrosis. ${ }^{2}$ Sometimes ascending infections may lead to salpingitis, peritonitis, pelvic inflammatory disease and other related complications.

Diagnosing a foreign body in the vagina of a young girl needs a high level of suspicion. Though pelvic radiograph, sonography or MRI may detect the foreign body in the vagina, a normal report does not rule out its possibility. Wu et al in 1995 reported a case of an 8 years old girl who presented with bloody discharge from vagina for more than 4 years. ${ }^{7}$ Multiple imaging modalities (pelvic X-ray, ultrasound and MRI of the pelvis) failed to find any evidence; yet vaginography revealed an intravaginal filling defect and later two foreign bodies, a round plastic tube and a cap were removed. So, direct visualization of vagina either in the outdoor or if needed, via examination under anesthesia is the best tool to diagnose. Sometimes if the foreign body is hard, it can be felt by the examining finger inserted into the rectum. A low placed foreign body in the vagina near the introitus may be visible only by gently separating the labia and, once visualized, may be removed by a small artery forceps, as it was in this particular case. But distally situated or embedded foreign body in the vagina may need an examination under anaesthesia and its visualization and removal by a vaginoscope. ${ }^{8}$ After removal, the vagina should be irrigated with povidone iodine solution.

Removing foreign body is the ultimate cure for these patients and after removal, if they have not been complicated by a long retained foreign body, such patients improve drastically.
Funding: No funding sources

Conflict of interest: None declared

Ethical approval: Not required

\section{REFERENCES}

1. Paradise JE, Willis ED. Probability of vaginal foreign body in girls with genital complaints. Amer J Dis Child. 1985;139(5):472-6.

2. Striker T, Narratil F, Sennhauser FH. Vaginal foreign bodies. J Paediatr Child Health. 2004;40(4):205-7.

3. Sanflippo JS. Gynaecologic problems of childhood. In: Sanflippo JS, eds. Nelson Textbook of Paediatrics. 16th ed. Philadelphia: WB Saunders; 2000.

4. Di Meglio G. Genital foreign bodies. Paediatr Rev. 1998;19(1):34.

5. Deligeoroglou E, Delivelioutu A, Laggari V, Tsimaris P, Creatsas G. Vaginal foreign body in childhood: a multidisciplinary approach. J Paediatr Child Health. 2006;42(10):649-51.

6. Capraro VJ. Vulvovaginitis and other local lesions of the vulva. Clin Obstet Gynaecol. 1974;1(3):533-51.

7. Wu MH, Huang SC, Lin YS, Lin MF, Chou CY. Intravaginal foreign body retained for a long duration. Int J Gynaecol Obstet. 1995;50(2):193-5.

8. Sahra Emamzadeh Fard, Haleh Naser Hojati, Koosha Paydary, Afshin Tajali, Abdol Mahammad Kajbafzadeh. Vaginal bleeding due to insertion of button battery: a case report and review of literature. Thrita. 2014;3(1):e15853.

DOI: $10.5455 / 2320-1770 . i j \operatorname{cog} 20150452$

Cite this article as: Chaurasia A, Gupta V, Mishra A. Vaginal foreign body in a 6 year old girl: a game for the child but a challenge for the gynaecologist. Int J Reprod Contracept Obstet Gynecol 2015;4:518-20. 